\title{
9 Can activist engagements have research outcomes?
}

\author{
The case of ACM and \\ participatory action research
}

\author{
Robert Fisher and William Jackson
}

\section{Introduction}

Adaptive learning approaches involving affected stakeholders are often advocated as an appropriate way to deal with complex and evolving situations in natural resource and environmental management or social development. Recognising that natural resource and environmental management involve social change, which experimental and reductionist science cannot easily address, some research institutions have introduced adaptive collaborative management (ACM), action research (AR) or particularly participatory action research (PAR) within their programmes. While the need for interdisciplinary research that involves mixed stakeholders is recognised, experience in applying such approaches shows that the scientific validity of the methods is often regarded with considerable scepticism within research institutions.

This chapter reflects on the experiences of the two authors in action research and, to a lesser extent, in ACM in a variety of institutions and contexts over more than three decades. ${ }^{1}$ Both authors first became involved in action research while working with the then Nepal-Australia Forestry Project (NAFP) in the late 1980s and early 1990s. Subsequently, RF taught in the School of Agriculture and Rural Development at the University of Western Sydney, Hawkesbury (UWS-H), from 1991 to 1996. At that time, most master's and $\mathrm{PhD}$ research in the School was undertaken as action research. RF supervised a number of action research-based master's and $\mathrm{PhD}$ theses, including the thesis by WJ (Jackson 1999). When Colfer, Prabhu and others at CIFOR began to develop CIFOR's ACM programme, RF became involved as an external partner engaged in action research training and subsequently with an ACM related writing workshop and editing a book on ACM with CIFOR researchers (Fisher, Prabhu and McDougall 2007). Finally, both RF and WJ were involved in the Livelihoods and Landscapes Strategy (LLS), a global programme of the International Union for Conservation of Nature (IUCN), which applied elements of action research methodology.

The chapter is very much about reflections on personal experiences. For the most part, we were both involved in what we understood as and referred to as action research, although our understanding of the method developed 
over time, as described later. Although our chapter title refers to participatory action research, the explicitly participatory version did not develop until later in our experience. When RF became involved with ACM, he continued to see AR, PAR and ACM as essentially cyclical and exploratory approaches that combined action and research to progressively work through complex and changing contexts in order to both learn about and improve them. This differed somewhat with the understanding within CIFOR which differentiated AR/PAR from ACM:

Our differentiation between adaptive collaborative management (ACM, an umbrella framework or approach) and participatory action research (PAR, a method) needs clarification. PAR shares with ACM the emphasis on facilitated and shared social learning in iterative cycles and on human resource development. But, unlike ACM, it can take place within a single group and address any topic of importance to the participants. CIFOR's version of ACM, on the other hand, requires attention to improving human well being, inter-group equity, health of forests (or other natural resources), to policy concerns, and collaborative work with other stakeholders or actors (at other levels or in other communities).

(Colfer 2013, 55)

While we acknowledge this distinction, our focus in this chapter is on the common features of ACM and AR/PAR as being concerned with both achieving research and interventionist outcomes. In particular, we want to show that both ACM and AR/PAR can produce research outputs while also leading to change.

\section{What were the concerns about ACM and action research?}

Colfer (2013; see also Chapter 1) discusses the experiences in developing and conducting ACM in CIFOR over an extended period. She is quite explicit about the early bias against ACM due to the reductionist preference among CIFOR's researchers. ACM was criticised as being unscientific for a variety of reasons, including the difficulty of scaling up from individual cases, and the replicability and generalisability of the research. It was later criticised because many of the publications from the ACM group did not fit CIFOR's "institutional preference for refereed journals in English" (Colfer 2013, 70), and there were even concerns about the non-standard format of social science publications compared with biophysical journals. Another issue

pertained to the general acceptance within forestry of the institutional and political status quo. Many scientists saw their roles as technical and decidedly not political... Yet within ACM there was broad recognition that a central goal was empowerment... of the women and men in forest communities, in their interactions with others.

(Colfer 2013, 51; see Chapter 8) 
Criticism of the ACM programme was explicit, often coming in meetings with the CIFOR board and from the director-general.

The trigger for this chapter came from the experiences of one of the authors (RF) who advised the ACM group from time to time and was a member of their international steering committee. RF did not directly observe the interactions between the ACM group and CIFOR management and other staff. He heard about the concerns and discussed them with the ACM team. $\mathrm{He}$ also observed negative attitudes from others at CIFOR, essentially in the context of "comments in the corridor" rather than public criticism. The criticisms faced by Colfer and other team members were much more explicit and direct.

The concerns about ACM described by Colfer are similar to concerns we have heard in the context of our work in action research outside CIFOR, although the concerns were generally less vehement. The main criticisms from scientists at CIFOR and other institutions were along the line that action research is not real science. The findings are not replicable or generalisable. In other words, AR misses some of the "hallmarks" of scientific processes. Such criticisms were often linked to scepticism about qualitative research generally. Colfer (2013) mentions this in the case of ACM at CIFOR.

As in the case of CIFOR, we were also exposed - in other contexts - to some discomfort about the combination of activism/intervention and research. However, this was not necessarily the same type of concern as that among the scientists at CIFOR. While researchers/scientists at CIFOR questioned ACM in terms of its research outcomes and the activist objectives, we have observed the reverse problem. Some activists were uncomfortable with combining social action/activism with research. Their concerns were twofold: the ideas that 1) research combined with development is exploitative, and 2) it is not the role of agencies concerned with development or sustainable development (see the later discussion of IUCN'S LLS).

This chapter deals with the problem of legitimacy in terms of both the concerns of scientists and activists. As it deals with our experiences, it focuses on action research, although we believe that the findings are relevant to ACM, which we see as essentially equivalent. The chapter will identify practical social and environmentally related outcomes from action research as well as research (knowledge) outcomes. It aims to show how action research (and ACM) can have multiple outcomes:

- Practical outcomes (such as improved practices or improved overall management);

- Social change outcomes (such as recognising existing local social organisations in forest management, acknowledgement of use rights and empowerment of women);

- Research outcomes (such as publications and dissemination including research publications). The research outcomes can include findings on useful methods and process documentation. 
The chapter will also briefly address questions about replicability and generalisability.

\section{What is action research?}

Kurt Lewin (1946) is generally regarded as being the first author to articulate action research as a method. He saw action research as a form of community experiment aimed at addressing social problems through collective action by a group. Even in this very early formulation of action research, Lewin talks of "circles" of "planning, executing, and reconnaissance or fact-finding" (Lewin 1946, 38) as the basis of planning subsequent steps:

Rational social management...proceeds in a spiral of steps each of which is composed of a circle of planning, action and fact-finding about the result of the action.

(Lewin 1946, 38)

As is evident from Lewin's work, the origins of action research are deeply rooted in social action and social change. Sometimes having social change objectives is seen as an essential element in definitions of action research. Greenwood and Levin $(1998,4)$ define action research as

social research carried out by a team encompassing a professional action researcher and members of an organisation or community seeking to improve their situation. AR promotes broad participation in the research process and supports action leading to a more just or satisfying situation for the stakeholders.

Greenwood and Levin specifically define action research as a type of social research. Fisher $(2002,41)$, in a positive review of Greenwood and Levin, has one "quibble." He suggests that " $[\mathrm{t}]$ he strong emphasis on $\mathrm{AR}$ as a form of social science may mask its potential relevance in the application of physical sciences." As we discuss in this chapter, AR can be and has been applied to environmental and resource management issues. We pursue the potential of action research's relevance to biophysical sciences in the context of community forestry and natural resource management, often in combination with action research as research for social change.

We see the key elements of action research as those identified by Kemmis and McTaggart (1988). ${ }^{2}$ Their book addresses AR specifically in the context of educational practices, but the elements are relevant more broadly. The key concepts link closely with the ideas of Lewin's seminal paper, particularly in the idea that the process is cyclical.

A key concept is the idea of a thematic concern, which is an "issue, or broad concern," rather than a specific research question. This is important in the examples of action research that we discuss later. For example, the work of 
NAFP in Nepal was not based on a specific research question, but a broad concern with a theme - such as the recognition that forest use and management needed to be handled better. The understanding of what specifically needed to be addressed evolved progressively through the project. More specific "research questions" could be defined for specific AR cycles.

Two of the other key elements of AR, as presented by Kemmis and McTaggart, are that it is a group activity in which group members participate in collectively addressing the thematic concern and that the process it follows involves a cyclical process of planning, acting, observing the results of action and reflection on the results and process. As a result of this reflection, a new cycle begins.

We suggest that Kemmis and McTaggart's approach is a useful way to conceptualise AR. However, we also suggest that it is useful to avoid being overly purist in applying it in different contexts.

In regard to the need to avoid being overly purist, we emphasise that the nature of participation and collaboration varies. It might involve a small core group of researchers and stakeholders tightly engaged in all aspects of a particular action research activity, including planning and evaluating action research cycles. Where the stakeholders consist of a large, dispersed population, it might involve some sort of representative structure. In other cases, there might be a core group, with other satellite groups being engaged at different levels in different aspects of a project. An example of this is an action research project on improving livelihoods and the performance of a government extension project in Papua New Guinea (Sriskandarajah and Fisher 1992). That project had a core group consisting of the researchers and national stakeholders in the project, with separate overlapping groups at district and sub-district levels.

We understand action research as a form of applied research (Fisher 2013). The essential differences between AR and other forms of applied research are the focus on exploratory, reflective and iterative inquiry and the participatory/ collaborative aspect.

Broadly speaking, applied research aims to address a situation or problem from a practical point of view, looking for a solution. The problem is often, but not always, defined by the owners of the problem rather than the scientist (which often makes it different from conventional research). Once the problem is defined, applied research can be implemented through more conventional approaches to science including the use of controlled experiments.

Action research differs from the more common linear approach to applied research in that it combines action and research and involves a group of people around an issue or concern. It involves consciously and systematically, moving through a series of repeated cycles of action, observation, reflection and planning. While more conventional applied research often involves the scientists going away to solve a research problem on behalf of a client, action research involves investigating issues at the same time as attempting to address them learning by doing and learning from doing. The solutions are tested and modified as the research proceeds. 
Action research is a process of learning in order to act more effectively in a particular situation. In this sense, it is first and foremost a methodology for implementation and action (Fisher and Jackson 1999). PAR is a form of action research that involves collaboration between researchers and people who are concerned with the need to solve a problem.

ACM has similar logic. It is about addressing problems collaboratively in a manner that adapts as the nature of the "problem" changes or as new problems emerge.

We suggest that it is important to differentiate between action learning and action research (Fisher 2013). Action learning is about learning approaches to problem solving. Like action learning, action research is about learning approaches to problem solving, but also about contributing to public knowledge by publication or other methods of dissemination of ideas/information. Unlike action learning

action research is... a type of research, in the sense that it contributes to "public" knowledge. Experience in a specific situation generates insights and understanding which can inform actions in similar situations. The word inform is important here. The intention is not to provide recipes for implementation, but rather to provide insights which others may find useful in other contexts. This aspect of generalising from learning in a specific situation is the research element.

(Fisher and Jackson 1999)

Both action learning and action research are useful when:

- a situation or issue is complex with many unknowns (and therefore not suitable to a reductionist approach);

- a situation is changing;

- the starting point is not clear;

- there are multiple stakeholders involved.

These situations commonly apply in cases involving the management of environmental and natural resources by humans.

\section{Our experiences with action research}

In the following section, we discuss our experiences with AR/PAR as we progressively became aware of the approach. The progression is from a naive stage when we were first exposed to some general ideas, through more informed stages as we were exposed to literature and wider experience. With our colleagues from the NAFP we started "by making it up as we went along," before becoming involved in a university programme where action research was central and later we took part in a more developed approach in the context of the IUCN LLS programme. 


\section{Nepal-Australia Forestry Project}

Australia has a lengthy history of involvement in forestry in Nepal, beginning in 1966 with a technical focus on forest nurseries and plantation establishment. By the late 1970s, the geographic focus of NAFP had shifted to the middle hills districts of Sindhu Palchok and Kabhre Palanchok, east of Kathmandu, and while the concern of the project remained largely on afforestation, it also began to widen to include community forestry.

In his description of the project in the late 1970s, David Griffin writes:

Forestation was said to be necessary to provide fuelwood, mainly for the Kathmandu Valley towns, and to arrest erosion on the surrounding hills. The initial solution was thought to be to plant fast growing, quick rotation exotic species in areas protected from the local populace by fences and guards. The very first advisor saw the weakness in such an assessment but for years the project remained in a largely technocratic mould.

(Griffin 1988, 23)

By the time we began working with NAFP in the late 1980s (we both joined in 1987), the thematic concern had shifted to a broader concern with improving both forest restoration and livelihoods. There was an increased focus on social questions, but this coexisted with the need to address other technical issues such as silviculture of natural forests and shrublands. Early efforts to develop forest management plans for communities failed when community consultations involved groups that were not traditional users of particular forests - the wrong people were identified (Gilmour and Fisher 1991). This led, progressively, to cycles of investigation (Lewin's "fact-finding") of developing methods for working with different "interest groups" within communities, ${ }^{3}$ identification of traditional users and studies of "indigenous" organisations and institutions of forest management. In parallel, cycles of more technical research took place on silvicultural issues related to meeting local needs and developing appropriate silvicultural techniques for communities. It is worth noting that the technical AR also involved collaboration with local forest users in terms of identifying the problems, undertaking technical interventions such as thinning of dense shrublands to promote the growth of locally preferred species and monitoring results.

These parallel and interlinked cycles were essentially action research cycles, illustrating the possibility that multiple AR cycles can occur at one time and that AR can usefully be applied to more conventional biophysical research.

By 1987, project staff, led by Project Director David Griffin and the Team Leader Don Gilmour, had begun talking about action research, but the discussion was barely informed by much, if any, of the literature or theory specifically related to action research. In fact, we were not exposed to the theoretical literature on action research until RF joined UWS-H in 1991. We did not consciously follow an action research cycle and there was no formal group of participants. 
In a brief paper, David Griffin (1987), the project director, questioned the meaning of intensified forestry in the context of mountain regions, arguing that the meaning of intensification needed to take account of linkages between forests and local communities. He then went on to suggest the relevance of participatory action research. In the same year, a conference paper by project staff (Gilmour, King and Fisher 1998) also argued the case for action research based on the inadequacy of traditional forestry research. Again, despite the use of the term, there was no specific reference to theoretical literature on action research. In fact, the case for action research was related to the work of Chambers (1986) on the "new professionalism" in development.

It appears that the origin of these publications and the concern with action research was in the movement that had been rethinking Himalayan mountain issues in the 1980s. In the context of increasing concerns by researchers about the high level of uncertainty about the real causes and effects of environmental degradation in the Himalaya, despite the commonly accepted view of a Himalayan mountain crisis, considerable work had been done calling the consensus into question. This questioning led to the Mohonk Conference in April 1986 in New York. The proceedings of the conference, which cover the findings of the critical research on the supposed crisis, are in an issue of Mountain Research and Development in 1987 (vol 7 no 3). Ives and Messerli (1989) also deal with the conference outcomes and show just how many of the common assumptions about the Himalayan environment added up to a myth.

Thus, it seems that the emergence of AR in NAFP was a consequence of the recognition that there were many unknowns about the Himalayan environment and development and recognition that scientific forestry was inadequate for addressing forestry in the Himalaya, specifically Nepal in the case of NAFP. The AR approach used in NAFP shifted progressively from focusing on improving awareness and capacity of local communities to restore and manage degraded forests using conventional forestry approaches, to working more closely with local people to identify challenges and potential solutions.

At the time we joined NAFP, concerns about the high level of uncertainty of data and information influenced our discussions within the project and with Department of Forest (DoF) colleagues. Given the social and environmental heterogeneity within the middle hills, the lack of reliable data and information meant that we had to constantly adapt the project as we learned. Although project staff did not widely use the term action research, and indeed much of the published literature on action research was not available to us at that time, we were engaged in what may be thought of as a naive form of action research. Nevertheless, almost intuitively, we engaged as a research team in a cyclical process of planning, acting, learning and reflecting. This process involved DoF staff and, informally, local forest users. We should stress here that, at this stage, there was no formal and ongoing involvement of local people as participants in the reflection process, but there was very active discussion with local people by staff as we trekked from village to village throughout the districts, staying in 
villages. We had not, at that time, developed a clear model for participation in PAR. In fact, we generally referred to the method as action research.

An essential feature of the process of engaging with local communities was the importance of identifying issues, stakeholders and conflicts before forming groups to plan community forest management. The risk of forming groups (community assemblies or committees) made up of the "wrong people" without legitimate interests in the form of recognised use rights was recognised very early, based on lessons from an abortive effort to set up a forest management plan at Chaap al Danda Forest through formal meetings (Gilmour and Fisher 1991). Following this abortive effort, participatory principles were applied without the project consciously practising PAR. The idea that forming a committee was not the first step contrasted with the usual bureaucratic practice of forest officers. They typically began community interventions by contacting local leaders and asking them to call a meeting without preliminary familiarisation with issues and stakeholders. This lesson could usefully be applied in contemporary programmes such as Forest Landscape Restoration and REDD+.

Had we, as part of the project team, not been afforded the flexibility of adapting the project as we learned, it is highly unlikely the project would have achieved the results that it did.

The exploratory approach adopted by the project enabled project staff to consider the validity of the generalisations and question the appropriateness of project interventions. One area of particular interest was indigenous ${ }^{4}$ management of forests. Gilmour and Fisher $(1991,17)$ note that:

The professional culture of foresters includes assumptions about the priority of technical knowledge about trees in all forestry activities. Such assumptions lead to a tendency to ignore the relevance of indigenous knowledge. They also lead to great difficulties in recognising the genuine multi-disciplinary nature of the activity we call community forestry.

The project began to explore the nature of indigenous forest management, and this revealed that a wide variety of indigenous systems and organisations existed, often in parallel with the formal government community forestry programme (at that time, the responsibility for forests was being handed over from the DoF to local governments, panchayats). We began to recognise that most hill forests had a set of users that were mutually recognised, that many had some form of indigenous forest management and that, in some cases, the panchayat approach to community forestry was leading to conflict when traditional users were disenfranchised from using a local forest or non-traditional users were empowered to use a forest. This revelation helped inform the shift to the user group approach to community forestry.

The research about indigenous forest management, undertaken as an outcome of the reflection in the action research process that this was an important knowledge gap, has been described in Gilmour and Fisher (1991) as well as in more conventional ethnographic literature (Fisher 1989, 1994). This 
emphasises that AR can include cycles of research in other modes and that it can contribute to more "conventional" literature.

It is important to stress here that, while the project was exploring social change through action research, a range of technical forestry issues, including silviculture of shrublands and harvesting of pine plantations to produce timber, were also explored through action research cycles. These simultaneous "action research" cycles interacted with each other as most project interventions had elements of social change and technical improvement.

\section{Outcomes of action research in the project}

NAFP was considered to be successful in several respects:

- In its early period, it was very successful in promoting and enabling reforestation with communities;

- The research into social aspects of forest management, including traditional or indigenous forest management, contributed to the development of community forestry policy and practice in the late 1980s and 1990s through close collaboration with senior DoF officials and policymakers - the approaches developed and community-level organisational models were incorporated in official guidelines and laws;

- The approaches to working with communities to collaboratively negotiate and plan community forestry activities were used as the basis of training activities and materials for DoF staff and were also published in a book (Gilmour and Fisher 1991) and a training manual (Jackson et al. 1996).

- The social aspects of research were published (including Gilmour and Fisher 1991; Fisher 1989, 1994). An important aspect of the published research is the process documentation of the social experiments (e.g., Gilmour and Fisher 1991).

- In terms of more conventional research, the project produced and disseminated a significant number of publications (including distributed reports and working papers) on social and biophysical topics as well as publications on the process of project intervention.

The experiences within NAFP certainly involved a relatively simple (even naïe) understanding of $A R$, and certainly, one in which participation was not formalised. The point that needs to be emphasised is that exploratory and cyclical research led to successful (and published or otherwise disseminated) research outcomes, as well as contributing to changes to community forestry policy and practice. The fundamental changes in policy and practice were 1) to support the separation of existing user groups from official political-administrative units that did not reflect use rights and 2) to contribute to the guidelines for forest department staff in implementing user group-based forestry. 


\section{Action research at the University of Western Sydney, Hawkesbury}

In the 1990s, AR was used in most, if not all, $\mathrm{PhD}$ and master's projects in the then School of Agriculture and Rural Development at UWS-H. ${ }^{5}$ The School was experimenting with quite radical new approaches to university teaching, at both the undergraduate and postgraduate levels. For postgraduate research (understood as master's or $\mathrm{PhD}$ level research in Australia), the emphasis was on combining social research with agriculture and natural resource concerns through action research. The field of social research is not synonymous with action research. The innovation at UWS-H was applying action research to social research.

The resulting theses dealt with a variety of problems. Some dealt with general development or rural development issues without being directly concerned with natural resource management. For example, Avorn Sansak (1996) applied what she called "collaborative action research" in the context of empowerment of women in a village in northern Thailand. She undertook her research as a facilitator of a core group of women who followed the cyclical action research process to improve their impact on decision making about village development. This was specifically concerned with social change but was not related to biophysical research.

Other theses addressed natural resource management or sustainable development issues, combining social and biophysical research. Solieng Mak (1997) explored agricultural innovation in rural Cambodia. Her initial focus was examining barriers to the adoption of green manuring in rainfed dryland rice farming. Promoters of green manuring had been puzzled by the poor level of uptake of the technology that demonstrably improved productivity. Solieng's work showed that the lack of "adoption" was due to a shortage of labour availability during the key period when the plants were maturing prior to being mixed with the soil. During this time, the growing plants were susceptible to free grazing cattle. Labour to guard the fields was not available. Men were busy during this time harvesting palm sugar, which was virtually the only available source of cash income. Women were occupied at home processing the raw material into palm sugar and looking after young children. A contributing problem was that the demographic structure was very biased towards small families with very few older adults to look after children. This was a result of the drastic demographic changes resulting from the Khmer Rouge period.

The emphasis further shifted to participatory research with villagers to address some of the identified issues, such as different ways of protecting rice plots in the context of shortages of labour and developing water supplies. One possibility was the use of collaborative groups to share labour. Initially, people were reluctant to become involved in working groups, a result of very negative experiences with agricultural working groups during the then-recent Khmer Rouge period. Later phases involved collaborative work digging ponds to store water for irrigation.

The research included a preliminary stage or cycle of what was essentially ethnographic research and then moved to further cycles of AR/PAR. The 
ethnographic work provided important findings on factors affecting the adoption of new technologies in post-conflict dryland Cambodia.

Mohammad Emadi's PhD (1995, further described in Emadi 2005) dealt with the frequently negative relationships between pastoral nomads and government officials in Iran. His research also began with an essentially ethnographic phase and moved to group meetings in which the different stakeholders discussed issues and conflicts and attempted to address them. A major finding of the ethnographic phase was that the problems facing nomads were perceived differently by nomads and officials. For officials, the key issue was damage to grasslands due to overgrazing. For nomads, key issues were the need to access services such as health and education for their families and the reduced access to grazing land due to spreading agriculture.

The action responding to these research findings focused on assisting government officials and academics to examine their assumptions and rethink their attitudes in a facilitated learning workshop (cf. Chapters 3 and 6, this volume, for more recent attempts to accomplish such goals). The practical outcomes were improved relationships and mutual understanding (i.e., social change).

Other theses addressed issues related to natural resources or agriculture, each involving PAR methodology in various ways.

Helen Ritchie (1998) worked with private landowners to address the problem of controlling water contamination from private land in Waikato, New Zealand. This was a complex practical problem involving collective action by individuals with strong commitments to private rights. The process involved the establishment of PAR groups. The research contributed to the theoretical literature on environmental governance.

Finally, Tevita Toafa (1994) carried out an action research project working with actors from the pumpkin industry in an effort to address the importance of the specific needs of the pumpkin market in Japan. Requirements included needs for reliable supplies in a narrow time window and pumpkin products to meet specified quality standards. The market was a niche market aimed to fill a gap in supply during a season when the supply could not be met from the main source - New Zealand. Like Ritchie's thesis, this involved encouraging people who were market competitors to collaborate through a participatory action research group in order to achieve common goals. From a research point of view, important findings involved improved understanding of group processes. The thesis also built upon and contributed to research on market chains.

It is important that all of these theses combined forms of PAR with a first phase in which the researcher(s) familiarised themselves with the context, including the physical and social landscapes (we think of this as an ethnographic phase). In particular, they identified the stakeholders who would need to be involved in planning and decision making. All of this was preliminary and was subject to further exploration. Additional stakeholders could be identified and added to the relevant PAR group. The essential element was that the process starts with an understanding of the, sometimes competing, interests of various stakeholders. PAR group formation is not a first step and must be informed. 
All of these theses had practical outcomes in terms of social change. They also contributed to knowledge in social fields and provided insights into action research methodology.

It is interesting to note here that, while this chapter accepts the premise that the scientific integrity of action research is often challenged, none of the external examiners of any of these theses criticised them as being "unscientific." In Australia, master's and $\mathrm{PhD}$ theses are examined by independent researchers rather than by the thesis advisors, so this indicates a level of openness to nonconventional research.

\section{The Livelihoods and Landscapes Strategy}

LLS was a five-year programme (2007-2011) implemented by IUCN and funded by the DGIS (Ministry of Foreign Affairs of the Netherlands). The Strategy focused on four main themes: poverty reduction, natural resourcebased markets and incentives, forest governance and landscape transformation (IUCN 2012).

LLS operated in a range of complex situations in 23 countries involving a wide variety of activities and a learning strategy focused on translating learning into policy-relevant messages. IUCN (2012) describes LLS as something of a laboratory to test widely held assumptions about the linkages between forest landscapes and livelihoods, for which limited, or only anecdotal evidence had been available. The LLS team included IUCN staff and consultants and more than 60 partner organisations in the countries involved.

The contexts of LLS activities in the 23 countries differed greatly. However, in each case, the context was complex, meaning there were many unknowns, and achieving collaboration with multiple partners with sometimes widely differing agendas and perspectives was challenging, to say the least. Action research was identified as one way of dealing with the need for collaborative problem solving. This led to an action learning and action research training workshop, involving participants from most of the LLS national teams, held in Tanzania in 2008.

Individual country teams had different approaches to implementing LLS. Several countries included action research in their activities. Examples from Ghana and China are discussed below.

The Wassa Amenfi West landscape (Nyame, Okai, Adeleke and Fisher 2012) forms part of the cocoa-producing area in southwest Ghana. In this area, there is a mix of land uses of which the principal agricultural activity is smallscale cocoa production by farmers who are mainly leaseholders. There are also often areas of degraded forests.

The LLS actions in the landscape were guided by a small team that consisted of LLS staff and relevant government officers. This group met regularly to review and evaluate activities. The PAR cycle was explicitly followed. This group was a structured group acting collaboratively to plan and implement action and research. 
As the project was operating in separate and dispersed communities, a single PAR group covering all sites and communities was not practical or desirable. In what can be understood as a sort of satellite structure, action research was also used at the community level in a less formal way, with community-level meetings. In these contexts, it again involved cycles of reflection and planning.

One important outcome involved addressing the reluctance of farmers to plant trees on their land, which was generally leased from local traditional leaders ("chiefs"). According to a Forestry Commission Directive, farmers had ownership of trees they planted provided the land was registered for the purpose of tree ownership - and not as certificates of land ownership or tenure. However, even when the land was registered, registration certificates were not provided, and farmers lacked confidence about their rights in the absence of evidence of registration. LLS designed a simple form, with details of registration, to be kept by farmers, thus increasing confidence through an informal innovation. The tenure innovation was reported in a publication on experiences in informal tenure reform in LLS (Fisher, Barrow, de Silva and Ingles 2012).

In China, the Miyun watershed ( $\mathrm{Li}$ and Emerton 2012) was one of the focal areas of the LLS programme. The watershed is an important source of water for Beijing. Occupancy and some use of the land were accepted by the government, but communities had no formal tenure rights. The government's emphasis on afforestation and protecting the watershed meant that community access for livelihood benefits in the watershed was restricted, and a logging ban prohibited most forest harvesting. To meet their fuelwood needs, local communities cut young undergrowth. This stopped the forests from naturally regenerating and halted ecological succession.

The protectionist emphasis on the management of the watershed was not achieving the balance of environmental and social outcomes that the government desired. The government, with the support of LLS, developed a villagebased participatory planning approach that led to the development of new local forest management plans. Use and management zones were agreed between government forest officers and local people for water protection, tourism and forest exploitation, informed both by community needs and the technical surveys carried out by the government and LLS staff, which documented forest status, resource availability and biodiversity. The PAR style approach taken to restoration in the Miyun watershed helped government staff to harmonise technical information with local interests and knowledge. The approach provided a better means for local people to use the forests at a sustainable level to meet their fuelwood needs while supporting watershed protection and conservation. It also contributed to the government exploring opportunities to integrate Forest Landscape Restoration into the activities of State Forest Farms, as demonstrated in an ongoing Global Environment Facility (GEF) supported project. $^{6}$

The practical results of activities in both landscapes were improved management of aspects of conservation and livelihoods. Most of the documentation 
of the activities provided insights on processes and problems that are relevant to people working on similar issues in other contexts rather than more broadly generalisable "research results." However, we would argue that such insights are research results (Fisher and Jackson 1999). The case studies were published in working papers. Such results are not peer-reviewed, but we argue that research outcomes are about "findings" or "lessons" that are disseminated in some way and may be useful in other similar contexts. This point is developed later.

For LLS, which was motivated and funded by donors to develop lessons about landscape approaches to conservation and livelihoods, research results were essential in order to enable lessons to be tried more broadly. Several regional writing workshops were held to support reflective report writing. There were several IUCN publications on specific issues and results from numerous countries, as well as a small number of papers published in journals. The work of LLS provided IUCN with knowledge that was used by the Government of Germany and IUCN to encourage governments to sign up to the Bonn Challenge to bring 150 million hectares of degraded and deforested landscapes into restoration by 2020 and 350 million hectares by 2030. The findings of LLS are also being used in the GEF project mentioned previously.

However, there was resistance from some of the LLS staff to the idea of action research and to efforts to encourage writing for publication. We believe that action learning (learning to improve action) was accepted, but some of the LLS team members were uncomfortable about combining activist concerns with research. They saw research as "exploitative" and both inappropriate and unnecessary in community-based conservation and development activities. They also asked why research was needed in LLS. This became a focus of disagreement at one global team meeting. Such concerns are the reverse of concerns by some scientists (as already discussed) that research should not be combined with activism.

\section{Discussion and conclusions}

We hope that the examples and experiences presented in this chapter contribute to addressing two apparently opposing concerns: the idea that ACM and $\mathrm{AR} / \mathrm{PAR}$ are poor methods for producing useful research on the one hand, and the idea that research cannot produce practical results in terms of social change or improved management on the other.

We have focused on AR rather than ACM because that is where we have had the most relevant experience. However, we believe that there is not much difference in practice because each aims for changes in practice as well as lessons that are useful beyond the immediate activity involved.

The examples given clearly show that AR can contribute to practical social or management changes and we do not intend to belabour that point. The key question here is to what extent there have been research outcomes. 
There are some clear examples of action research leading to the understanding of social phenomena. Examples from the chapter studies include:

- Solieng Mak's research finding explaining that Cambodian dryland rice farmers were unable or unwilling to adopt green-manuring technology because of labour shortages and the wariness of agricultural groups (learned during the Pol Pot period).

- Mohammad Emadi's finding that the concerns of nomads were more about accessing sedentary social services than access to pasture.

- Action research in Nepal leading to an increased understanding of indigenous forest management organisations (Gilmour and Fisher 1991; Fisher 1989, 1994).

However, demonstrating that action research may have concrete findings may not address the more general concern of quantitative/reductionist scientists that action research, like qualitative research in general, does not produce replicable or generalisable results. We suggest that the problem with that is that action research deals with cases that are context and time specific. The data cannot be confirmed by subsequent researchers because the situation has changed. ACM and PAR are meant to be applied to specific contexts in space and time. Nevertheless, insights gained through the processes may be useful in understanding and intervening in different cases.

Another point to consider is that action research is not necessarily or essentially about gathering information, such as information about numbers of trees, survival rate of trees, population numbers and so on. It is generally about increasing understanding of interactions between people, understanding implementation processes or understanding decision making. As Fisher and Jackson (1999) state "Action research focuses more on increasing understanding than on collecting facts (although these can be collected under the rubric of action research when necessary)."

In action research, much of what is learned is in the form of insights about causes and effects in a specific situation. The insights are not generalisable in the same way the results of laboratory experiments are, but they may be useful for understanding other situations where some similar conditions exist. For example, understanding why people do not adopt technology in one situation (because of risk or labour shortage) may not be universal, but it is an insight that may be helpful in other cases.

Most programme/project interventions in natural resource management still tend to favour approaches that are based on available evidence using a theory of change or a results-based approach that makes assumptions about the social and socio-ecological situation, which then the programme/project proceeds to try and improve. Often, the complexity of the situation is not well understood at the start of a programme/project but emerges with time. Programmes/projects are often not well equipped to adapt to an emerging understanding of a situation but are driven by a need to deliver agreed results that were (often 
incorrectly) identified at the start of a programme/project. PAR and ACM were meant to help address this problem.

Based on our experiences, and many others documented, we suggest that action research, following an exploratory cyclical approach, is of great value in contributing to contemporary programmes such as Forest Landscape Restoration and REDD+. In both of these programmes, implementation occurs in the context of many unknowns - social, political and biophysical. There are often, if not usually, major unknowns that can affect results, including different tenure systems, different types of local institutions and different policies. Action research allows action to start without a full understanding of the situation and to be modified as more becomes known or as the situation changes. We also suggest that a hybrid approach to action research, which encompasses both social research and biophysical research is ideally suited to these programmes.

\section{Acknowledgements}

We would like to thank Dr Don Gilmour, who was the Team Leader of NAFP when we first experienced action research, and the late Emeritus Professor David Griffin, who was the project director. Both led the way with action research in those days and our experience in Nepal would have been much reduced if not for their leadership and willingness to question. We would also like to thank our colleagues in NAFP, both Nepali and expatriate as well as our colleagues within the Department of Forests. We also acknowledge Professor Richard Bawden, Dr Nadarajah Sriskandarajah, Dr Mohammad Emadi and other colleagues at the University of Western Sydney, Hawkesbury, as well as our colleagues in IUCN for sharing their knowledge and experience in action research.

\section{Notes}

$1 \mathrm{RF}$ is an anthropologist. WJ was trained as a forester but has also worked in a wide range of conservation roles.

2 There is a more recent edition of Kemmis and McTaggart. We refer to the 1988 edition as that was the edition to which we were first initiated at UWS-H and which influenced all of our subsequent work.

3 The application of methods such as focus groups was introduced in parallel with training workshops for Department of Forests field staff, led by Dr Kaji Shrestha (a Nepali adult education specialist) and activist and Jane Gronow, a British volunteer.

4 In project documentation and publications, the term indigenous referred to locally initiated management arrangements and local knowledge. It did not refer to the institutions or knowledge of "indigenous" groups (i.e., minority ethnicities). Retrospectively, the better word might have been "endogenous." but we use the term as it was used in our documents at the time.

5 As is common in universities that have the endless tendency to reorganise, the name and organisational structure of the unit changed several times in the period 1991-1996, although what we refer to as the School remained a recognisable entity. 
6 See the GEF project - Building Climate Resilient Green Infrastructure: Enhancing Ecosystem Services of Planted Forests in China through Forest Landscape Restoration and Governance Innovation. Accessed 7 March 2021. https://www.thegef.org/project /building-climate-resilient-green-infrastructure-enhancing-ecosystem-services-planted -forests.

\section{References}

Chambers, Robert. 1986. "Normal Professionalism, New Paradigms and Development." Discussion Paper 227, Institute of Development Studies, University of Sussex.

Colfer, Carol J. Pierce. 2013. "The Ups and Downs of Institutional Learning: Reflections on the Emergence of Adaptive Collaborative Management at the Center for International Forestry Research." In Adaptive Collaborative Approaches in Natural Resource Governance: Rethinking Participation, Learning and Innovation, edited by Hemant R. Ojha, Andy Hall and Rasheed Sulaiman V., 48-102. London and New York: Earthscan.

Emadi, Mohammad H. 1995. "Pastoralists, Participation and Policy: An Action Oriented, Systemic and Participatory Approach to Improve the Relationships Between Pastoralist Nomads, Government and Natural Resources in Iran." PhD Thesis, University of Western Sydney, Hawkesbury, Australia.

Emadi, Mohammad Hossein. 2005. "Research Through Action with Nomadic Pastoralists in Iran." In Participatory Research and Development for Sustainable Agriculture and Natural Resource Management: A Sourcebook. Volume 1. Doing Participatory Research and Development, edited by Julian Gonsalves, Thomas Becker, Ann Braun, Dindo Campilan, Hidelisa de Chavez, Elizabeth Fajber, Monica Kapiriri, Joy Rivaca-Caminade and Ronnie Vernooy. Ottawa, Ontario, Canada: International Development Research Centre.

Fisher, Robert. 1989. "Indigenous Systems of Common Property Forest Management in Nepal.” Working Paper 18. Honolulu: East-West Environment and Policy Institute, EastWest Center.

Fisher, Robert. 1994. "Indigenous Forest Management in Nepal: Why Common Property is Not a Problem." In Anthropology of Nepal: People, Problems and Processes, edited by Michael Allen, 64-81. Kathmandu: Mandala Book Point.

Fisher, Robert. 2013. "Learning through Action: Reflections on Action Research in Natural Resource Management." In Adaptive Collaborative Approaches in Natural Resource Governance: Rethinking Participation, Learning and Innovation, edited by Hemant R. Ojha, Andy Hall and Rasheed Sulaiman V, 257-286. London and New York: Earthscan.

Fisher, Robert, Edmund Barrow, Janaka de Silva, Andrew Ingles and Gill Shepherd. 2012. "Improved Access to Forest Resources: Experiences in Informal Tenure Reform from IUCN's Livelihoods and Landscapes Strategy." Working Paper 3, Livelihoods and Landscapes Strategy. Gland, Switzerland: IUCN.

Fisher, R.J. 2002 "Review of Introduction to Action Research: Social Research for Social Change (Davydd J. Greenwood and Morten Levin).” Practicing Anthropology 24 (1): 41.

Fisher, R.J. and W.J. Jackson. 1999. "Action Research for Collaborative Management of Protected Areas." In Collaborative Management of Protected Areas in the Asian Region, edited by Krishna Prasad Oli, 235-243. Kathmandu: IUCN Nepal. Proceedings of a Workshop held at Royal Chitwan National Park, Sauraha, Nepal, May 25-28, 1998.

Fisher, Robert J., Ravi Prabhu and C. McDougall, eds. 2007. Adaptive Collaborative Management of Community Forests in Asia: Experience from Nepal, Indonesia and the Philippines (ACM Series). Bogor, Indonesia: CIFOR. 
Gilmour, D. A. and R. J. Fisher. 1991. Villagers, Forests and Foresters. Kathmandu, Nepal: Sahayogi Press.

Gilmour, D.A., G.C. King and R.J. Fisher. 1998. "Action Research into Socioeconomic Aspects of Forest Management." In Role of Forest Research in Solving Socioeconomic Problems in the Himalayan Region. Proceedings of IUFRO Symposium, Peshawar, Pakistan, 1727 October 1987.

Greenwood, Davydd J. and Morten Levin. 1998. Introduction to Action Research. Social Research for Social Change. Thousand Oaks, London and New Delhi: Sage Publications.

Griffin, David. 1987. "Intensified Forestry in Mountain Regions." Mountain Research and Development 7 (3): 254-255. Proceedings of the Mohonk Mountain Conference: the Himalaya-Ganges Problem.

Griffin, David. 1988. Innocents Abroad in the Forests of Nepal. An Account of Australian Aid to Nepalese Forestry. Canberra: ANUTECH Pty Ltd.

IUCN. 2012. Livelihoods and Landscapes Strategy: Results and Reflections. Gland, Switzerland: IUCN.

Ives, J. D. and B. Messerli. 1989. The Himalayan Dilemma: Reconciling Development and Conservation. London and New York: The United Nations University-Routledge.

Jackson William, Y. B. Malla, A. W. Ingles, H. B. Singh and D. A. Bond. 1996. Community Forestry for Rural Development in Nepal. A Training Manual. Kathmandu, Nepal: NACFP.

Jackson W.J. 1999. “The Dynamics of Lekh Forest Use in the Middle Hills of Nepal.” PhD Thesis, University of Western Sydney, Hawkesbury.

Kemmis, Stephen and Robin McTaggart, eds. 1988. The Action Research Planner. Australia: Deakin University, Deakin University Press (3rd edition).

Lewin, Kurt. 1946. "Action Research and Minority Problems.” Journal of Social Issues 2 (4): 34-46.

Li, J. and L. Emerton. (2012) Moving Closer to Nature: Lessons for Landscapes and Livelihoods from the Miyun Landscape, China. Strategy Working Paper 1. Gland, Switzerland: IUCN (LLS).

Mak, Solieng. 1997. "Rainfed Lowland Rice Farming in Cambodia: A Study of Agricultural Change." PhD Thesis, University of Western Sydney, Hawkesbury.

Nyame, Samuel Kofi, Michael Okai, Adewale Adeleke and Bob Fisher. 2012. Small Changes for Big Impacts: Lessons for Landscapes and Livelihoods from the Wassa Amenfi West Landscape, Ghana. Landscape Paper 4. Gland, Switzerland: IUCN (LLS).

Ritchie, Helen. 1998. "Beyond the Fences: Co-ordinating Individual Action in Rural Resource Management through Landcare. A Case Study of Managing Non-point Source Discharges to Water in Waikato, New Zealand." PhD Thesis, University of Western Sydney, Hawkesbury, Australia.

Sansak, Avorn. 1996. "Empowering Women in Rural Development: A Collaborative Action Research Project in Northern Thailand." PhD Thesis, University of Western Sydney, Hawkesbury, Australia.

Sriskandarajah, N. and R.J. Fisher. 1992. "A Participatory Approach to Improving Rural Livelihoods of People in the Goilala District of Papua New Guinea." Report on a research project funded by the Australian International Development Assistance Bureau under the Development Research Grants Scheme.

Toafa, Tevita. 1994. "Action Research to Improve the Pumpkin Industry in Tonga." MSc Thesis, University of Western Sydney, Hawkesbury, Australia. 